\title{
UNDERSTANDING BEHAVIOURAL DESIGN: INTEGRATING PROCESS AND COGNITIVE PERSPECTIVES
}

\author{
Khadilkar, Pramod Ratnakar; Cash, Philip \\ Technical University of Denmark
}

\begin{abstract}
Behavioural design is a crucial research area due to its potential in leveraging the positive outcomes of traditional design. Current need for theory building requires discerning the unique characteristics and challenges of behavioural design. To contribute towards this goal, the paper structures the conceptual and operational uniqueness of the behavioural design using the process and cognitive perspective. Process model uses the basic design cycle to discern the tasks and stages of behavioural design. Cognitive perspective uses dual process theory and cognitive strategies used by designers. Integrated model of process and cognitive perspective is the crucial contribution of this paper. A case study involving interview of lead designers from five behavioural design consultancies has been used to present and elaborate the usefulness of the integrated model of behavioural design. Integrated perspective links the process characters like incomplete analysis, simulation and evaluation stages, over reliance on the prescriptive methods, and unequal emphasis to multiple disciplines, with incomplete analytical process, and solution and knowledge driven strategy along cognitive perspective
\end{abstract}

Keywords: Human behaviour in design, Behavioural design, Design cognition, Design theory

\section{Contact:}

Khadilkar, Pramod Ratnakar

Technical University of Denmark

Management Engineering

Denmark

pramod.khadilkar@gmail.com

Cite this article: Khadilkar, P.R., Cash, P. (2019) 'Understanding Behavioural Design: Integrating Process and Cognitive Perspectives', in Proceedings of the 22nd International Conference on Engineering Design (ICED19), Delft, The Netherlands, 5-8 August 2019. DOI:10.1017/dsi.2019.192 


\section{INTRODUCTION}

Behavioural design is an area of rapidly growing real world and research importance (Cash et al., 2017). For example, a European Technical Report highlighted that increases in sustainable energy use of up to $20 \%$ are yet to be realized through behaviour change. In this context, behavioural design has produced long-term improvements in, for example, electricity consumption (up to 13\%), waste (up to 32\%), water use (up to 7\%) (Abrahamse et al., 2005). Meta-analysis also shows that users receiving behaviour change interventions reported significantly better outcomes on physical activity than those in control conditions (effect size (d) 0.21) (Taylor et al., 2012). Thus, behavioural design offers great potential and it will become an increasingly important aspect of design.

Behavioural design delivers products and services that offer new means for supporting people to behave in desired ways (Tromp et al., 2011) e.g. by evoking, nudging, persuading or motivating. This not only prevents rebound, which can reduce efficiency gains by as much as $50 \%$ (Greening et al., 2000), but is also more effective, sustainable, and ethical, since it aligns user and societal interests (Tromp et al., 2011). However, while there are a wide range of possible change mechanisms (Michie, Atkins, et al., 2014b), current behavioural design processes and methods struggle to address how to leverage interaction between these mechanisms (Nielsen et al., 2018). This limits the effectiveness of current behavioural design interventions (Cash et al., 2017; Tromp, 2014). For example, translation of the psychology literature is fragmented to specific design phases and approaches, such as user understanding (Daae and Boks, 2018) or behavioural conceptualization (Lockton et al., 2010). This challenge directly translates to a theoretical need for conceptual synthesis and relationship building (Cash, 2018), to identify connections between multiple design process and method descriptions. This elaborates the challenges linked with design practice beyond the process aspect. This paper explores the potential of fundamental cognitive theory for developing a more cohesive behavioural design methodology.

This paper contributes a novel conceptualisation of behavioural design using insights from psychology and design. This is realised by conceptually mapping the characteristics/dimensions to the process and the cognition of the behavioural design. This is operationalized by the initial exploratory case to examine and elaborate the theoretical understandings. Section 2 of the paper elaborates the unique characteristics of behavioural design. Section 3 presents the integrated perspective towards the behavioural design by combining the process and cognitive perspectives. Section 4 uses a case study to examine and elaborate the findings of the section 3. Section 5 discusses the findings and presents the future research scope.

\section{UNDERSTANDING THE COMPLEXITY OF BEHAVIOURAL DESIGN}

The understanding of the behavioural design along the dimensions of task, process and designer (Dorst and Dijkhuis, 1995) is essential. The task and process dimensions significantly diverge from traditional design as follows,

\subsection{Task dimension}

Extending Simon's basic definition, behavioural design can be about changing the current behaviour to desired behaviour. In addition to the contextual factors, behaviour is the outcome of the mechanisms that are innate to a person. This additional task of understanding, using, steering the innate mental mechanism differentiates behavioural design from traditional design conceptualisations that focus on external factors to evolve technologies, systems, services and process to serve our society (Andreasen et al., 2015). This shift in design focus brings along the difficulties associated with understanding and deliberately changing behaviour. This is rooted in the fact that behaviour is the outcome of knowledge, beliefs, motives and desires that are inside the individual, which is unobservable (Fishbein and Ajzen, 2010). Similarly, it is impossible to evaluate the extent to which an intervention is able to change these internal mechanisms, unlike a more efficient machine or a handle that fits the users hand or a process that is more streamlined etc. which could be objectively tested. Using an external cue, i.e. behaviour, to interpret the mental mechanism is a classical challenge. This leads to approximations and thus uncertainty of the outcomes. Choice of an environmentally friendly product by an individual could be an approximation of her sustainable behaviour. This could be true, or could be influenced by other external factors. The same person can behave unsustainably in other 
circumstances at the same time. Although it is possible to ask about beliefs, motives and intentions to perform a behaviour, it is difficult and approximate (Fishbein and Ajzen, 2010). For desired behaviours that are unknown to the target user, the intention to behave will be a coarse approximation. This leads to low predictability and errors like literal inconsistency where stakeholder behaves in a completely opposite manner to what is intended earlier (Fishbein and Ajzen, 2010). Thus, the behavioural design task is conceptually different due to its focus on mental mechanisms and the unique uncertainties associated with understanding and changing behaviour.

Being linked to traditional design, behavioural design tasks are not excluded from the complexities of traditional design. In terms of technical complexity behavioural design tasks can include technical complexities, e.g., cockpit design, societal complexities, e.g., crime prevention (Asquith et al., 2013), etc. In terms of scope, the tasks could extend from product, e.g., desks to aid physical activity, service, e.g., mobile apps to measure physical activity; to include the whole system, e.g. design of the hospital to make children feel safe under CT scanner (Taking Better Care of Children, 2013). Thus, behavioural design encompasses more factors than traditional design solutions, and interfaces directly with areas such as policy, education and social change.

\subsection{Process dimension}

Behavioural design is a complex process. The conceptual challenges cascade to an operational level that demands context and time specific observation of current behaviour and testing of desired behaviour. Collecting this data is more resource intensive than traditional design. Analysing behaviour involves conducting surveys, interviews to gauge factors like attitude towards the behaviour, perception about how socially relevant 'others' judge the behaviour, competency to perform the behaviour (Fishbein and Ajzen, 2010), etc. These factors are difficult to measure, simulate, evaluate and predict, as they are innate to an individual (see Section 2.1). Further, contextual social factors also influence these innate factors over the time. A compendium of theories on public health lists 83 theories with 1659 constructs. This is a good indicator of the task and context specificity of behavioural design problems (Michie, West, et al., 2014a). Characterizing problematic and desired behaviour/s has specific steps, such as defining it in terms of the action, target, context and time; differentiation based on stability, high or low opportunity, frequent/infrequent (Fishbein and Ajzen, 2010), positive/negative, new/familiar (Fogg and Hreha, 2010) etc. Characterization of individuals could involve understanding the background factors like personality, education, income, knowledge (Fishbein and Ajzen, 2010). Context also can be characterized based on familiarity, stability etc. Ideating for a desired situation demands knowledge about interventions that are most effective in bringing about the change and thus need conceptualization and synthesis of a 'best' solution from a large pool of solutions (Lockton et al., 2010; Michie et al., 2013). In domains like public health, the behavioural goal is not a distinct straightforward behaviour, but a complex mix of multiple behaviours governed by multiple stakeholders, and with unpredictable links between an intervention and desired behavioural outcome (Michie, West, et al., 2014a). Testing involves measuring the intent towards the target behaviour in a similar context and along similar time dimensions. This is as complex as measuring a behaviour. Evidently, the 'The Human Behaviour-Change Project' seeks the power of Artificial intelligence and Machine learning to tackle this complexity in structuring the health behaviour and in generating possible interventions (Michie et al., 2017).

At a process level, literature does not elaborate all the steps of behavioural design. Specifically there are few design methods to help formulate, measure and characterize behaviour. The complexities discussed above also point towards a need for a methodology to support behavioural design. In particular, a methodology would support the development of coherent process and problem models, which have been found to be critical to shape effective design work via the 'design centre' concept (Girard and Robin, 2006). Although, literature presents numerous specific discussions associated with e.g. ethics (Berdichevsky and Neuenschwander, 1999), sustainability (Tromp et al., 2011), or health (Fishbein and Yzer, 2003). No current framework addresses the challenges described in this section, and has the potential for the development of a 'design centre' for behavioural design. It is also important to understand the effects of these unique characters on how designers design. Given this context, a candidate for such an integrative perspective can be drawn from human cognition, which connects design processes, design conceptualisation, and human behaviour i.e. offering a potential to connect the task, process and designer dimensions of the behavioural design. 


\section{BEHAVIOURAL DESIGN: PROCESS AND COGNITIVE PERSPECTIVES}

This section describes behavioural design from two perspectives. The design process perspective covers the complexities of the task and process, while the cognitive perspective represents the cognitive mechanisms that a designer could adopt to tackle the inherent complexities of behavioural design.

\subsection{Design process perspective}

The design process is crucial to understanding the conceptual and temporal flow of design work (Dorst and Dijkhuis, 1995). However, differentiating between the overall goal of design and the behavioural component is important due to their distinctive challenges, timelines and design tools (Cash et al., 2017). Here we use a basic design cycle representation of the behavioural design process to structure the activities in a way consistent with prior design process conceptualisations. Generic design activities are:

1. Analysis: defines an intervention's 'technical, psychological, economic and cultural' functions

2. Synthesis: generates provisional designs to the problems identified in analysis

3. Simulation: builds the prototypical models of the provisional design/s using the theories and knowledge from past to understand how they might work, look and function

4. Evaluation: compares the expected outcome with the derived models from simulation

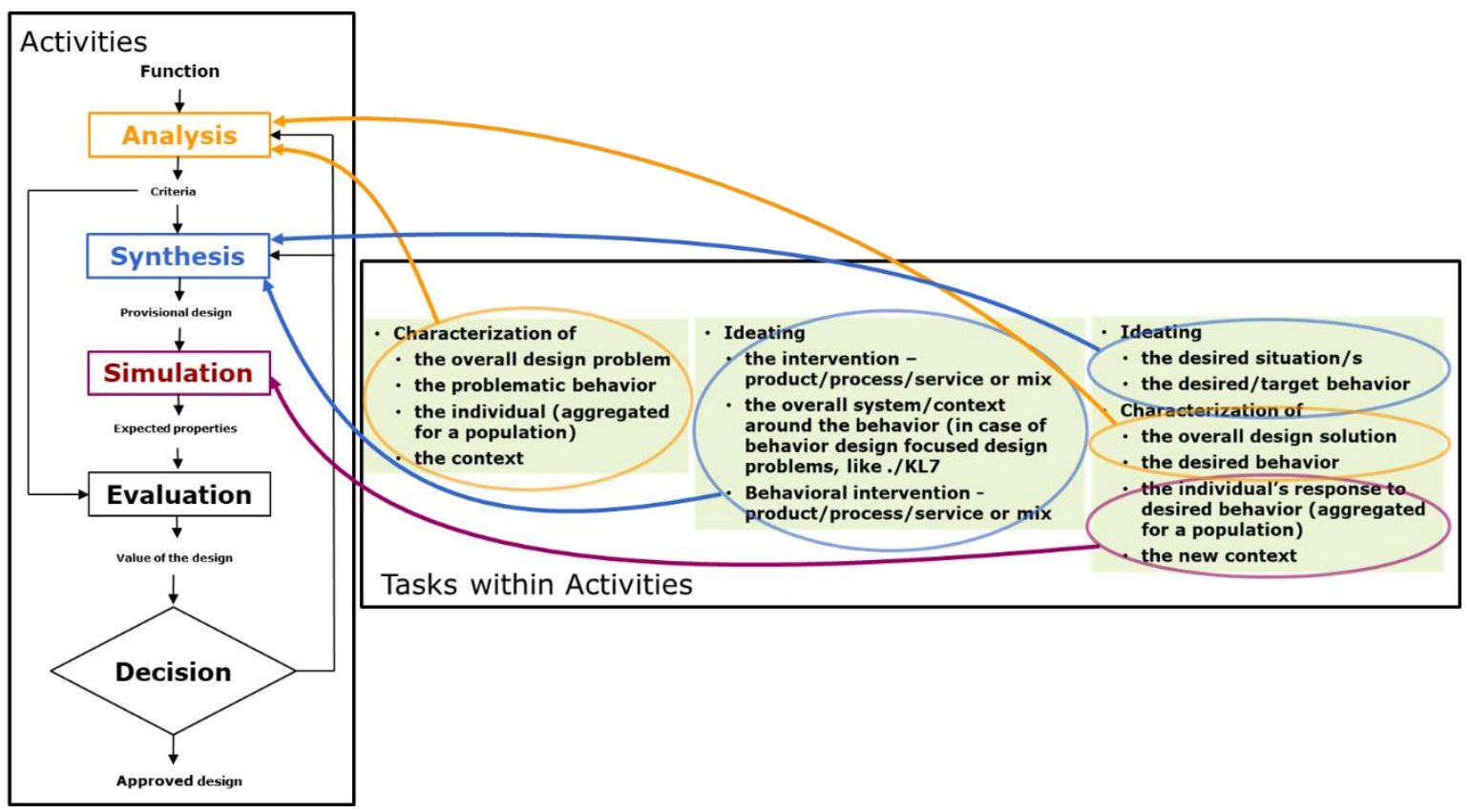

Figure 1: Process perspective of behavioural design

Figure 1 maps the basic tasks (with green background) associated with behavioural design to the generic activities of the design cycle. Behavioural design always start with the characterization of the problematic behaviour. The characterization of individual and context essentially require tracing back problematic behaviour's roots into human psychology (see Section 2.1). The desired behaviours need to be ideated and then characterized in detail to ideate the product/process/service that can fulfil the desired situations. The ideated desired behaviour and intervention then must be simulated and evaluated against the goals generated in the analysis. The back arrows at decision shows the iterative nature of behavioural design. Each behavioural design activity has unique behaviour related tasks and challenges. However, this perspective is not sufficient, in isolation, to elaborate the way a designer handles these tasks.

\subsection{Cognitive perspective: an early attempt}

Currently there are no perspectives that represent the 'designer' dimension of behavioural design. However, at the centre of a design work is the designer, who drives the cycles of decision-making and iteration illustrated in Figure 1. Design is reflection in action (Schon, 1983) and designers can have different cognitive activities based on their expertise level (Kavakli and Gero, 2002) or based on the uncertainties involved in the design activity (Cash and Kreye, 2017). Cognition is an important perspective to understand design from designer's perspective. A dominant theory in this cognitive 
domain is dual process theory, which we use to help understand the designer. Like any other individual, a designer has the interconnected systems of thought referred as Type 1 and Type 2 (Kahneman and Egan, 2011). Type 1 is autonomous and fast. Type 1 response is executed without control of the rational mind when a triggering stimulus is encountered. Type 1 processes are rapid and can happen in parallel (Stanovich, 2011). Humans predominantly operate in Type 1 mode due to its efficient and faster operation (Kahneman and Egan, 2011). This mode is crucial to the overall efficiency of human cognitive actions. In contrast, Type 2 processes are rational, reflective in nature, and demand mental processing. Type 2 processes are relatively slow and follow a serial chain of interrelated decisions (Stanovich, 2011). Importantly, Type 2 processes happen after overriding Type 1 processes. This needs hypothetical reasoning about possible outcomes that may not exist currently, which uses simulation of hypothetical models where the causes and effects of the responses are tested. This simulation requires decoupling from reality, and hypothetical models. A development in cognition research (Stanovich et al., 2011) explains overriding and decoupling. This conceptualization identifies three 'minds' that govern the various extents of Type 1 and Type 2 processes. Type 1 processes are guided by the Autonomous mind that uses the compartmentalized and structured knowledge from past experiences (Stanovich, 2011). Type 2 processes involves both the Algorithmic mind and Reflective mind. The Algorithmic mind thinks causally, using strategies and generation of hypothetical situations. This brain employs logical and probabilistic reasoning. The Reflective mind is about 'why' something should be done, i.e., the goals, related beliefs and the choices that can realize those goals. Reflective mind initiates the overriding of the Type 1 processes and decoupling that allows simulation of possible responses. The Autonomous mind continues to help by providing readymade knowledge if situations are routine, which improves efficiency by reducing the mental load.

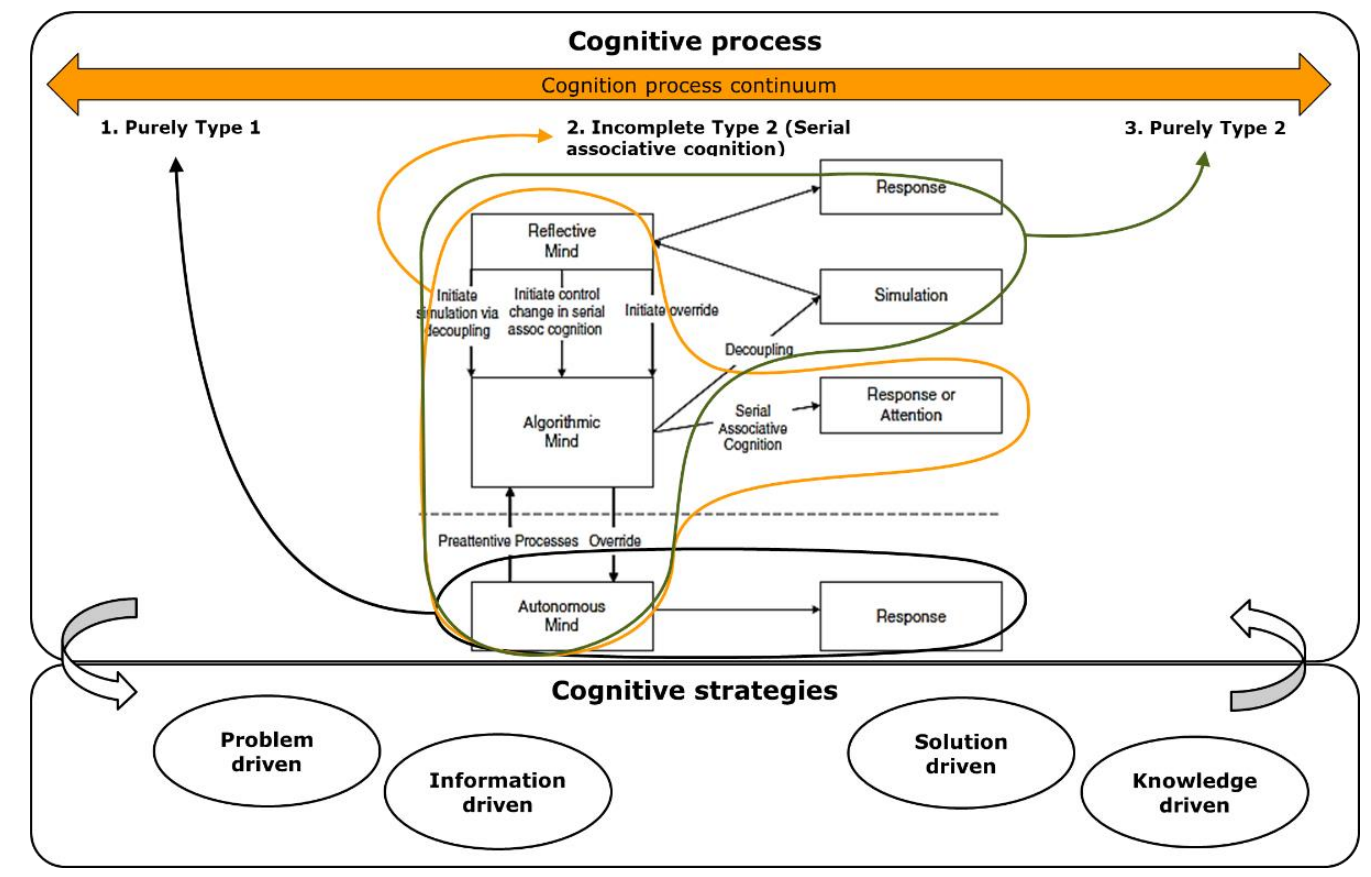

Figure 2: Initial cognitive perspective of design - part of the image is sourced from (Stanovich, 2009)

Literature suggests that there is a continuum of cognitive function from Type 1 to Type 2 (see the upper part of Figure 2). Three conceptually distinct ways are elaborated here. The first conceptual way is of purely Type 1, where the Autonomous mind provides automatic response to a situation using the time tested and highly compacted knowledge about cause and effects. Here, the response is not generated through analytical processes. In the second way, the Reflective mind initiates a trigger to override the default response of Autonomous mind and tries to respond to a situation through decoupling and simulation using Algorithmic mind. However, instead of rationally evaluating all hypothetical alternatives it falls to own bias. This is referred to as serial associative cognition with focal bias (Stanovich, 2009). In the third way, after an override, a complete and thorough decoupling and simulation is achieved resulting into a thorough rational process of selecting a response. However, the outcome of the third way depends on the extent of knowledge and metal abilities linked with each 
mind, referred to as mindware (Stanovich, 2009). As such, thorough rational process are also prone to errors similar to autonomous process if the mindware is not sufficient or has errors. This is referred to as 'mindware gaps' and 'contaminated mindware' (Stanovich, 2009). Either of the three way cognitive processes could result into an apt response, yet the chances of producing a rational response to a complex and new situation improves with the third way. Many of these elements are related to how designers operate while designing. Research shows that designers employ cognitive strategies while designing, like problem driven, information driven, knowledge driven and solution driven (Kruger and Cross, 2006). The cognitive processes relate to the cognitive strategies (see the lower part of Figure 2). The problem focused strategies that create analytical abstractions of the problem and then effectively evaluate the solution concept, are closer to Type 2 processes. While solution and knowledge driven are more like Type 1 and incomplete Type 2, respectively. Thus, the cognitive perspective shows how a designer responds to a situation. However, this needs to be integrated with understanding of the task in order to understand behavioural design.

\subsection{Integrating process and cognitive perspectives of behavioural design}

A primary aspect of how designers execute the design process is their cognition, which is influenced by the characteristics of the design task and process, e.g., various design methods influence student designer's perceived time pressure, motivation and effort spent (Daalhuizen et al., 2014) and the structuredness of a design technique affect the cognitive style of a designer (Gero et al., 2013). On the other hand, experienced designer's cognitive styles affect the effectiveness of the outcomes of various design activities (Kruger and Cross, 2006). Importantly, the process perspective provides a useful structure for pin-pointing and correlating the different activities and tasks that are effective and contribute towards the success of the intervention (Cash et al., 2017). Earlier research utilizes the effect of one perspective over another, however, it is not used in an integrated manner to elaborate a specific design variant like behavioural design.

Independently the two perspectives provide only partial information. The process perspective cannot elaborate inter-stage comparison, like why designers are effective in one stage and not in another, and inter-designer comparison, like why experts are effective and novices are not. On the contrary, the cognitive perspective is very difficult to operationalise without the structure of the process perspective. Thus, an integrated perspective can correlate the effect of a unique behavioural design task, e.g. characterising behaviour, on the cognitive process. As such, the integrated perspective provides a distinct overview not provided by prior models of design.

\section{DESIGN CASE STUDY}

In order to better understand the utility of this integrative perspective, an initial, exploratory case study was undertaken. In particular such an approach is well suited to developing new understanding where theory is limited (Handfield and Melnyk, 1998), as is the case here. Companies that specifically identify themselves as working in behaviour design domain and with proven experience from the country 'Denmark' were identified and contacted. Five companies voluntarily accepted to collaborate. All the companies were reputed behavioural design companies in Denmark. At least one lead designer was interviewed from each company. Each designer has been involved in complete design cycle of multiple behavioural design projects and understand the challenges involved in it. The aim was to understand characteristic features of their practice, design processes and common challenges they face in this context. The interviews followed a semi-structured guide. The headline questions and the rationale (in brackets) are listed below:

1. How do you generally plan a design project that focuses on behaviour change? (to understand the behavioural design process vis a vis type of task allocated in industrial setup)

2. How do you define and map out the behaviour? (Process/Cognitive perspective - To understand the rigor of the analytical process during cognition)

3. Do you ever use or rely on behavioural theory in your projects? (To check how the existing knowledge is used and to understand the mindware requirements)

4. Do you see any day to day challenges in the process? (to understand the challenges linked with overall design task of behavioural design)

5. How do you define project success and how do you determine whether you reach it or not? (to explicitly understand the criteria used to evaluate the outcomes) 
Interviews took approximately 1 hour each, and in addition, secondary data was collected from standard process descriptions, common issues, and project reporting. Each interview was transcribed and via axial coding the key issues were distilled. The examination and evaluation of these were presented back to the case companies as a robustness check.

\subsection{General observations}

The case companies understand the conceptual difference that underlines behavioural design, i.e., its dependence on human behaviour, yet they are not able to explicitly elaborate what qualifies as a behavioural design project. The case companies explicitly highlight the operational challenges linked with the context, the time pressure and budget pressures. Most of the companies follow the basic design cycle process but not in a rigid way. The composition of the teams include experts in psychology and in creative design. Most of the projects are of 3 to 4 months in duration, some stretching up to a year. Designers clearly understand the importance of theory yet they agree that it is impossible to go as deep as they wish to due to resource limitations. Overall designers are influenced by prescriptive theories like Theory of heuristics and biases (Tversky and Kahneman, 1974), behavioural wizard (Fogg and Hreha, 2010), etc. Simulation as a design activity has never been explicitly discussed. The implicit assumption could be that, the solutions will work as they are based on empirically tested prescriptive theory. However, none of the designers explicitly confirm this bias. In general pilot testing was not widespread due to the constraints placed on the projects by clients. The initial interpretations of observations on the process and cognition perspectives are presented in Table 1 below.

Table 1: Interpretation of case study observations along process and cognitive perspective

\begin{tabular}{|c|c|c|}
\hline $\begin{array}{l}\text { Process } \\
\text { description }\end{array}$ & Observations & $\begin{array}{l}\text { Cognitive description } \\
\text { (possible interpretations) }\end{array}$ \\
\hline & $\begin{array}{l}\text { Unanimous acceptance about 1) methodical and } \\
\text { conceptual complexity of behavioural design, 2) } \\
\text { infeasibility of understanding all the theoretical aspects } \\
\text { of a behaviour }\end{array}$ & $\begin{array}{l}\text { Incomplete type } 2 \text { cognitive } \\
\text { process }\end{array}$ \\
\hline \multirow[t]{2}{*}{$\begin{array}{l}\text { Incomplete or } \\
\text { premature analysis }\end{array}$} & $\begin{array}{l}\text { Major emphasis on observed behaviour and allocating it } \\
\text { to specific category of biases/heuristics rather than } \\
\text { holistic understanding of the psychological factors }\end{array}$ & $\begin{array}{l}\text { Incomplete type } 2 \text { cognition } \\
\text { process with focal bias }\end{array}$ \\
\hline & $\begin{array}{l}\text { Usage of own back catalogues, and prescriptive theories } \\
\text { and models of behavioural design (Tunnel vision) }\end{array}$ & $\begin{array}{l}\text { Incomplete type } 2 \text { cognitive } \\
\text { process with focal bias, and } \\
\text { Knowledge driven strategy }\end{array}$ \\
\hline $\begin{array}{l}\text { Incomplete } \\
\text { analysis and } \\
\text { simulation }\end{array}$ & $\begin{array}{l}\text { Critical analysis of desired behaviour is not as } \\
\text { emphasized as of problematic behaviour }\end{array}$ & Solution driven strategy \\
\hline $\begin{array}{l}\text { Incomplete or } \\
\text { absent simulation }\end{array}$ & $\begin{array}{l}\text { Measurement of intentions towards desired behaviour } \\
\text { is absent. Rare instances pilot studies using available } \\
\text { resources outside the use context }\end{array}$ & $\begin{array}{l}\text { Incomplete type } 2 \text { cognition } \\
\text { process with override failures }\end{array}$ \\
\hline \multirow[t]{2}{*}{$\begin{array}{l}\text { Incomplete } \\
\text { simulation/ } \\
\text { evaluation }\end{array}$} & $\begin{array}{l}\text { Acceptance that it is impossible to test the behavioural } \\
\text { intervention and it can change completely while } \\
\text { dissemination/implementation }\end{array}$ & \\
\hline & $\begin{array}{l}\text { Difficulties in handing over inferences from one } \\
\text { discipline expert (behavioural psychologist) to other } \\
\text { (creative designer), from one stage (analysis) to other } \\
\text { (synthesis) }\end{array}$ & $\begin{array}{l}\text { mindware gaps and mindware } \\
\text { contaminations }\end{array}$ \\
\hline
\end{tabular}

The exploratory case studies revealed the following significant results. First, though case companies use the activities of basic design cycle, they are solution and knowledge focused in their cognitive strategy. This is observed from the process perspective where designer's analysis of a behaviour is based on the prescriptive theories and back catalogues. Designers accept that their primary strategy is to identify the bias related to the problematic behaviour.

Secondly the behavioural design tend to be towards incomplete Type 2 cognitive process as simulation is largely missing from the design process. This could be due to the lack of methods and tools related 
to simulation. Evaluation is also unstructured. The lack of the evaluation is compensated by adaptation and improvement of intervention during implementation/dissemination.

Thirdly, the process is unequally interdisciplinary in nature. This means some experts, like psychologists, are in charge of front end design activities like analysis and other experts like creative designers are in charge of synthesis. This may result in mindware gaps. Both experts, i.e., psychology expert and creative design expert have their unique and developed mindware, however, they are owners of different activities of design cycle. The designer may not be able to use the mindware of the psychologist completely if they are not involved during the ideation and redesign stage.

Fourthly, the unequal multidisciplinary nature of the process results into the myside bias, which could result in mindware contaminations if the two domain experts are not empathetic and respectful towards each other.

\section{DISCUSSION AND FUTURE RESEARCH DIRECTIONS}

The outcomes of the study are in sync with the literature about design process. There is extensive literature that shows that use of theory in design of public health interventions is low (Michie and Abraham, 2004). The over reliance on prescriptive theory also show the narrow vision towards behaviour resulting in common misunderstandings like 'it is just about common sense', 'people act rationally', 'people act irrationally', and 'it is possible to predict accurately' (Kelly and Barker, 2016) affecting the quality of the interventions. The study also suggests that behavioural design projects should be planned to allocate money, time and human expertise differently. Specifically, allocating more resources to understand and test behaviour, for in context pilot studies and for longer overlap between behaviour psychologist and designer; allocating longer project times for continued designer engagement during dissemination.

The results linking design process to cognitive process offer some initial insights. The study does not intend to establish relationships between the integrated perspective and the success of the interventions in practice. Further, this study does not conclude or connote that a specific cognitive process or strategy is necessarily bad or good. However, it shows that the integrative lens provides a unique way to elaborate understanding of current practice in a specific domain. The interpretations are presented in the Figure 3.

The integrated perspective shows multiple directions for research in behavioural design. First, it essentially demands that knowledge from psychology has to be situated in design nomenclature. Currently only prescriptive knowledge has been employed, which could lead to Type 1 or Incomplete Type 2 ways as described in Section 3.2, for example, trying to fit current behaviour in one of the bias category from theory of bias and heuristics, and using a standard solution category from design with intent. Design based yet descriptive methods from psychology should be made available to behavioural designers. Traditionally design has not extensively integrated behavioural simulation (Roozenburg and Eekels, 1995) and it has a lot of scope for design research. Evaluation of behavioural design solutions may need proxies like intent from psychology, which could be brought into mainstream design. Empirical studies on the relation between cognition of the designer and the unique challenges in behavioural design could help in understanding both process and cognitive perspectives. This study identified a number of cognitive challenges faced by a designer in dealing with behavioural design. Overall this research points to the potential of an integrated perspective for better understanding of the problems faced by behavioural designers, and as a framework for developing support in this domain.

Theorization of cognition in behavioural design and empirical studies about success of design with the nature of cognitive activity are two critical research directions. Further, an empirical study of how behavioural design is practiced and its correlation with the success in terms of actual behavioural change is essential to develop the behavioural design research. 


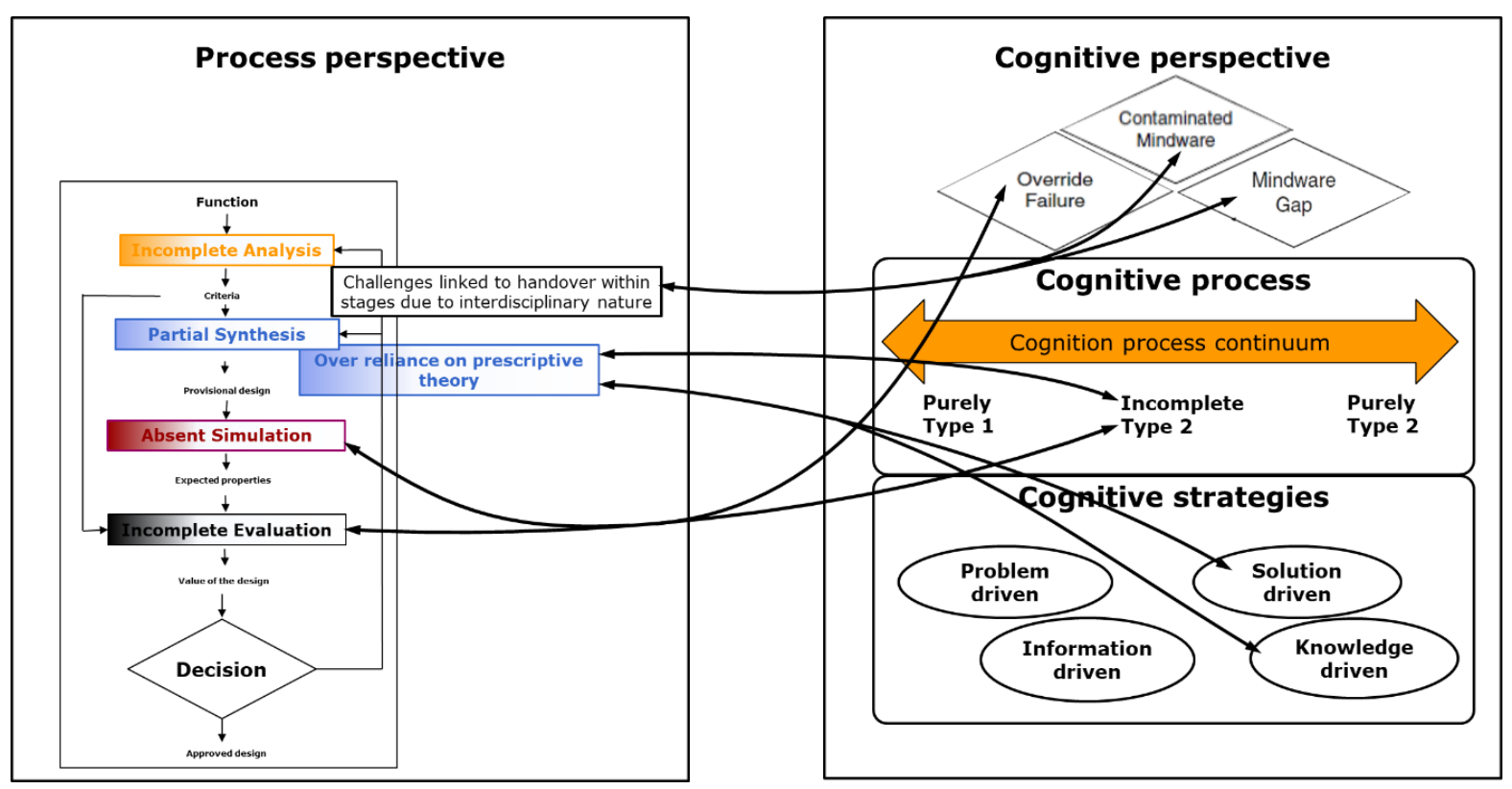

Figure 3: Behavioural design from integrated perspective of process and cognition

\section{CONCLUSIONS}

Behavioural design has unique challenges over traditional design. This paper elaborated these challenges in a structured way to distinguish behavioural design as a unique design domain. An integrated process/cognitive perspective is used to understand behavioural design with respect to three crucial dimensions of design, i.e., task, process and designer. This provides significant potential for elaborating understanding of behavioural design. An initial case study shows the usefulness of the integrated perspective in elaborating the observations. By integrating the cognitive perspective our integrated view structures a number of directions for further research focused on understanding the unique difficulties associated with behavioural design.

\section{REFERENCES}

Abrahamse, W., Steg, L., Vlek, C. and Rothengatter, T. (2005), “A review of intervention studies aimed at household energy conservation”, Journal of Environmental Psychology, Elsevier, Vol. 25 No. 3, pp. 273-291.

Andreasen, M.M., Hansen, C.T. and Cash, P. (2015), "Change, Development, and Conceptualization: Setting the Scene", Conceptual Design, Springer, pp. 13-34.

Asquith, L., Dorst, K., Kaldor, L. and Watson, R. (2013), "Introduction to Design+Crime", Crime Prevention and Community Safety, Vol. 15 No. 3, pp. 169-174.

Berdichevsky, D. and Neuenschwander, E. (1999), "Toward an ethics of persuasive technology", Communications of the ACM, ACM, Vol. 42 No. 5, pp. 51-58.

Cash, P. and Kreye, M. (2017), "Uncertainty Driven Action (UDA) model: A foundation for unifying perspectives on design activity”, Design Science, Cambridge University Press, Vol. 3, p. e26.

Cash, P.J. (2018), "Developing theory-driven design research”, Design Studies, Elsevier, Vol. 56, pp. 84-119.

Cash, P.J., Hartlev, C.G. and Durazo, C.B. (2017), "Behavioural design: A process for integrating behaviour change and design”, Design Studies, Elsevier, Vol. 48, pp. 96-128.

Dorst, K. and Dijkhuis, J. (1995), "Comparing paradigms for describing design activity”, Design Studies, Elsevier, Vol. 16 No. 2, pp. 261-274.

Daae, J. and Boks, C. (2018), "Tweaking interaction through understanding the user", in Niedderer, K., Cllune, S. and Ludden, G. (Eds.), Design for Behaviour Change, Routledge, New York, USA, pp. 74-92.

Daalhuizen, J., Person, O. and Gattol, V. (2014), “A personal matter? An investigation of students' design process experiences when using a heuristic or a systematic method", Design Studies, Vol. 35 No. 2, pp. $133-159$.

Fishbein, M. and Yzer, M.C. (2003), "Using theory to design effective health behavior interventions", Communication Theory, Wiley Online Library, Vol. 13 No. 2, pp. 164-183.

Fishbein, M. and Ajzen, I. (2010), Predicting and Changing Behavior: The Reasoned Action Approach, Psychology Press, New York, USA. 
Fogg, B.J. and Hreha, J. (2010), "Behavior wizard: A method for matching target behaviors with solutions", International Conference on Persuasive Technology, pp. 117-131.

Gero, J.S., Jiang, H. and Williams, C.B. (2013), "Design cognition differences when using unstructured, partially structured, and structured concept generation creativity techniques", International Journal of Design Creativity and Innovation, Taylor \& Francis, Vol. 1 No. 4, pp. 196-214.

Girard, P. and Robin, V. (2006), "Analysis of collaboration for project design management", Computers in Industry, Elsevier, Vol. 57 No. 8-9, pp. 817-826.

Greening, L.A., Greene, D.L. and Difiglio, C. (2000), "Energy efficiency and consumption - the rebound effect a survey", Energy Policy, Elsevier, Vol. 28 No. 6-7, pp. 389-401.

Handfield, R.B. and Melnyk, S.A. (1998), "The scientific theory-building process: a primer using the case of TQM", Journal of Operations Management, Elsevier, Vol. 16 No. 4, pp. 321-339.

Kahneman, D. and Egan, P. (2011), Thinking, Fast and Slow, Vol. 1, Farrar, Straus and Giroux New York.

Kavakli, M. and Gero, J.S. (2002), "The structure of concurrent cognitive actions: a case study on novice and expert designers", Design Studies, Elsevier, Vol. 23 No. 1, pp. 25-40.

Kruger, C. and Cross, N. (2006), "Solution driven versus problem driven design: strategies and outcomes", Design Studies, Elsevier, Vol. 27 No. 5, pp. 527-548.

Lockton, D., Harrison, D. and Stanton, N.A. (2010), "The Design with Intent Method: A design tool for influencing user behaviour", Applied Ergonomics, Elsevier, Vol. 41 No. 3, pp. 382-392.

Michie, S., Richardson, M., Johnston, M., Abraham, C., Francis, J., Hardeman, W., Eccles, M.P. et al. (2013), "The behavior change technique taxonomy (v1) of 93 hierarchically clustered techniques: building an international consensus for the reporting of behavior change interventions", Annals of Behavioral Medicine, Oxford University Press, Vol. 46 No. 1, pp. 81-95.

Michie, S., Thomas, J., Johnston, M., Aonghusa, P. M., Shawe-Taylor, J., Kelly, M.P., Deleris, L.A. et al. (2017), "The Human Behaviour-Change Project: harnessing the power of artificial intelligence and machine learning for evidence synthesis and interpretation", Implementation Science, Vol. 12 No. 1, p. 121.

Michie, S.F., West, R., Campbell, R., Brown, J. and Gainforth, H. (2014a), ABC of Behaviour Change Theories, Silverback Publishing.

Michie, S. and Abraham, C. (2004), "Interventions to change health behaviours: evidence-based or evidenceinspired?", Psychology \& Health, Taylor \& Francis, Vol. 19 No. 1, pp. 29-49.

Michie, S., Atkins, L. and West, R. (2014b), "The behavior change wheel: a guide to designing interventions", Great Britain: Silverback Publishing.

Nielsen, C.K.E.B.B., Cash, P. and Daalhuizen, J. (2018), “The behavioural design solution space: examining the distribution of ideas generated by expert behavioural designers", Ds92: Proceedings of the Design 2018 15th International Design Conference, pp. 1981-1990.

Roozenburg, N.F.M. and Eekels, J. (1995), Product Design: Fundamentals and Methods, John Wiley \& Sons Ltd, West Sussex, England.

Schon, D. (1983), The Reflective Practitioner: How Professionals Think in Action, Basic books.

Stanovich, K. (2009), "Distinguishing the reflective, algorithmic, and autonomous minds: Is it time for a triprocess theory", In Two Minds: Dual Processes and beyond, pp. 55-88.

Stanovich, K. (2011), Rationality and the Reflective Mind, Oxford University Press.

Stanovich, K., West, R. and Toplak, M. (2011), "Intelligence and rationality”, Cambridge Handbook of Intelligence, pp. 784-826.

Taking Better Care of Children. (2013), , available at: https://www.philips.es/cdam/b2bhc/us/whitepapers/healthcare-experience-solutions/130532_AE Pediatrics CS_ReadOnly.pdf.

Taylor, N., Conner, M. and Lawton, R. (2012), "The impact of theory on the effectiveness of worksite physical activity interventions: a meta-analysis and meta-regression", Health Psychology Review, Taylor \& Francis, Vol. 6 No. 1, pp. 33-73.

Tromp, N. (2014), Social Design: How Products and Services Can Help Us Act in Ways That Benefit Society, TU Delft, Delft University of Technology.

Tromp, N., Hekkert, P. and Verbeek, P.-P. (2011), "Design for socially responsible behavior: a classification of influence based on intended user experience”, Design Issues, MIT Press, Vol. 27 No. 3, pp. 3-19.

Tversky, A. and Kahneman, D. (1974), "Judgment under uncertainty: Heuristics and biases", Science, American association for the advancement of science, Vol. 185 No. 4157, pp. 1124-1131.

\section{ACKNOWLEDGMENTS}

This project has received funding from the European Union's Horizon 2020 research and innovation programme under the Marie Skłodowska-Curie grant agreement No 754462. Authors thank Ms. Beatrice Angel and Ms. Nanna Kristiansen for planning, conducting and documenting the interviews used in the case study. We also thank the case companies for participating in the study. 